\title{
The young surgeons' page
}

\author{
Ara A. Vaporciyan, MD, ${ }^{\mathrm{a}}$ Stephen C. Yang, MD, ${ }^{\mathrm{b}}$ and James I. Fann, $\mathrm{MD}^{\mathrm{c}}$
}

\footnotetext{
From ${ }^{\mathrm{a}}$ Department of Thoracic and Cardiovascular Surgery, MD Anderson, Houston, Tex; ${ }^{\mathrm{b}}$ Division of Thoracic Surgery, Johns Hopkins University, Baltimore, Md; and ${ }^{\mathrm{c}}$ Department of Cardiothoracic Surgery, Stanford University, Stanford, Calif.

Disclosures: Authors have nothing to disclose with regard to commercial support.

Received for publication Sept 10, 2018; accepted for publication Sept 10, 2018; available ahead of print Nov 15 , 2018.

Address for reprints: James I. Fann, MD, Department Cardiothoracic Surgery, Stanford University Medical Center, Falk CVRC, 300 Pasteur Dr, Stanford, CA 94305 (E-mail: jfann@stanford.edu).

J Thorac Cardiovasc Surg 2019;157:669-70

0022-5223/\$0.00

Published by Elsevier Inc. on behalf of The American Association for Thoracic Surgery https://doi.org/10.1016/j.jtcvs.2018.09.030
}

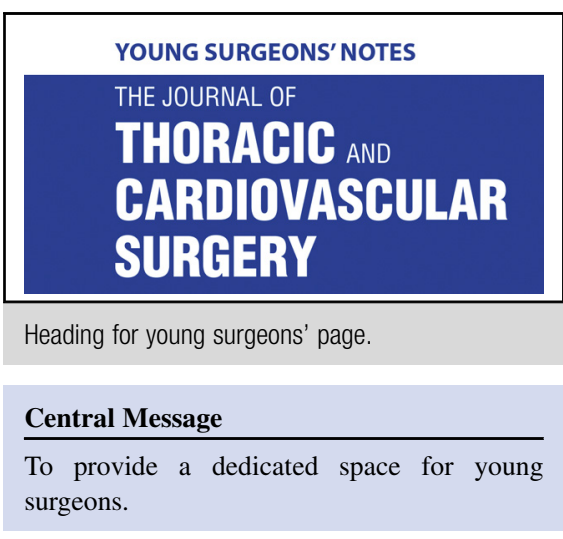

How does a specialty journal increase its value to the professionals it serves? This has been a central focus and directive of the editorial team led by Dr Richard Weisel since he took the reins as Editor-in-Chief. The barriers are significant. First is the near oppressive competition for time that affects all members of the profession. Second, the omnipresence of mobile access and an increasing volume of online reviews can diminish the value of reading individual investigations and reflecting on their applicability to practice. Finally, one must consider the mountain of publications that inundate our inboxes from an ever-growing number of journals.

Although these hurdles appear daunting, there is another transformation that is influencing how members of a profession-or for that matter anyone on the planet_-gather new information and knowledge. Journals, and really all forms of print publication, have been the mainstay of knowledge dissemination since Johannes Gutenberg democratized their availability. In 1450, when his first press began production, there were fewer than a million books on the planet. Within 50 years, 50 million books were in circulation. This massive influx of information initiated a tectonic societal change. John Lienhard, in his book How Invention Begins, ${ }^{1}$ outlines the massive social influence this sudden influx of knowledge had on humanity. These religious, political, and technological changes continue to be felt more than 500 years after the first books came off the press.

But this mode of knowledge dissemination is increasingly less dominant. The Internet provides ubiquitous access to information through open-source publications and social media. Ideas can be shared nearly instantaneously. The old model of a privileged or handpicked source of new knowledge is being threatened by an open-source model facilitated by the Internet. Couple that with the fact that the Internet is $<30$ years old and we begin to realize that greater influence is yet to come.
Readily available access to knowledge and ideas can be beneficial, but there is an inherent weakness: There is no reliable method to verify the content. Simply put, there is no filter. Any thought, belief, perception, suggestion, or opinion can be disseminated. The noise that such an approach produces can be deafening. So, although the Internet has challenged the utility of professional journals as vehicles for transmission of knowledge, it has also provided an opportunity for journals to innovate and address the many recognized drawbacks of the Web.

This opportunity is being seized by Dr Weisel and the Journal of Thoracic and Cardiovascular Surgery (JTCVS). The intent is to create a space for open, thoughtful, evidence-based discussions that focus conversations and cut through the noise created by postings on the Web. Commentaries and editorials solicited to accompany highquality articles has been 1 means to provide greater insights into research. Additionally, relevant work from other journals is highlighted, providing access and a forum for further reflection and discussion. Furthermore, space has been devoted for younger members of our profession, who are drawn to the Web, to voice their interests and concerns. This approach provides a unique and fresh view of our profession, a view that will allow a more complete understanding of all facets of our specialty, including diverse surgeon populations - from early trainees to those reflecting on their career.

We began with 2 strategies: The first was to bring the print media to the Web by leveraging social media. Working with the editorial staff of The Annals of Thoracic Surgery and a cadre of dedicated young surgeons, the Thoracic Surgery Social Media Network (@TSSMN) was created. This group worked with Drs Weisel and Patterson to identify articles of relevance from their respective journal. The articles 
would be designated open access then linked to a Twitter chat that would allow open discussion of the work. The second approach was to invite young surgeons to engage with the print version of JTCVS by providing editorials addressing topics of interest and relevance to them. Initially, the topics of interest centered on issues widely recognized as pertinent to young surgeons just entering practice. However, as more of these editorials began to appear, issues relevant to the wider population of surgeons emerged. From the reviews, it became clear that the topics often crossed generations and were widely applicable with input from multiple sources.

Allowing an open exchange of ideas enriches our profession. Cardiothoracic surgery is dynamic, and changes in health care finance, outcomes reporting, acuity of patient populations, technology, and surgical education are just a few of the hurdles to overcome. Innovation is more than ever accomplished by merging existing concepts rather than creating something new.

Young surgeons are frequently at the point of the spear when adapting to changes in health care, technology, and new responsibilities. That-combined with their limited voice in print- justifies the need to maintain their role as originators of editorials. However, young surgeons' editorials can benefit from other views to more broadly reflect the interests of all readers. To achieve this end, we chose a framework adapted from an approach first advanced by the Journal of the American College of Cardiology. ${ }^{2}$ Briefly, JTCVS will accept an initial outline of a proposed editorial describing its overall goal and proposed arguments. Examples include topics relating to training, mentorship, professional development, research initiatives, application of new technologies, and issues unique to international trainees. ${ }^{2}$ There will no longer be an invitation from the editors to submit an article for the Young Surgeons' Page. Rather, any interested young surgeon can submit an outline describing his or her proposal. We suggest that young surgeons should be within 5 years of the completion of their formal training. We also hope that a mentor will be recruited to assist with the preparation of the proposal. After the outline is submitted and reviewed by a group of associate editors and reviewers, suggestions will be provided to the author(s) with an opportunity to submit revisions. Once an approved version is generated, the authors will be invited to submit the manuscript that will undergo a formal review similar to conventional submissions.

The goal is simple: Provide a voice and a dedicated space for young surgeons, allow them to apply that voice in the creation of meaningful dialog centered on topics of broad interest to our readers, and leverage that open dialog to stimulate innovation in our profession.

\section{References}

1. Lienhard JL. Part III: Writing and showing. In: Lienhard JL, ed. How Invention Begins Echoes of Old Voices in the Rise of New Machines. 1st ed. London, England: Oxford University Press; 2006:137-216.

2. Sharma G, Cullen MW, Sinha SS. How invention begins echoes of old voices in the rise of new machines. J Am Coll Cardiol. 2017;69:104-5. 